Original Research

\title{
Using a Rocking Chair in the Care of People with Dementia: A Single- Case Research Study
}

\author{
Annelie K Gusdal ${ }^{*}$, Christine Gustafsson
}

School of Health, Care and Social Welfare, Mälardalen University, Eskilstuna/Västerås, Sweden; EMails: annelie.gusdal@mdh.se; christine.gustafsson@mdh.se

* Correspondence: Annelie K Gusdal; E-Mail: annelie.gusdal@mdh.se

Academic Editor: James S. Powers

OBM Geriatrics

2020, volume 4, issue 2

doi:10.21926/obm.geriatr.2002114
Received: November 09, 2019

Accepted: March 27, 2020

Published: April 07, 2020

\begin{abstract}
The people with dementia experience a progressive loss of cognition, while more than $90 \%$ of them develop behavioral and psychological symptoms of dementia (BPSD). BPSD may result in physical injuries and psychological distress among people with dementia and their family/caregivers. First-line care strategies in dementia care should not unthinkingly involve pharmacological interventions to avert or reduce the behavior, and should rather consider the person and their unique requirements. Therefore, a combination of pharmacological and non-pharmacological interventions is strongly recommended. Since the care staff in dementia care is required to be informed regarding the non-pharmacological approaches to address BPSD, the present study was aimed to evaluate the use of a rocking chair in the context of BPSD, quality of life, and medication usage among people with dementia at individual level. The secondary aim of the present study was to describe care staff's experiences related to the feasibility and usability of rocking chair in providing care for PwD in a nursing home setting. The present research is a single-case study, performed using a mixed-methods approach, with six people having dementia and 11 care staff members in a nursing home setting. The people with dementia used the Wellness Nordic Relax ${ }^{\circledR}$ Chair for a mean number of five times/week, for eight weeks in total. Quantitative and qualitative data were collected prior to, during, and post-intervention (A-B-A design). The quantitative and qualitative data were consistent with each other. The mean, median, and relative change
\end{abstract}

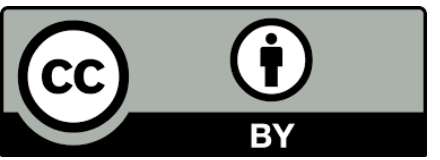

(C) 2020 by the author. This is an open access article distributed under the conditions of the Creative Commons by Attribution License, which permits unrestricted use, distribution, and reproduction in any medium or format, provided the original work is correctly cited. 
measures indicated a decrease in the BPSD symptoms, such as aberrant motor behavior, agitation, apathy, depression, irritability, and night-time behavior disturbances, and increased quality of life upon using the Wellness Nordic Relax ${ }^{\circledR}$ Chair. It was also considered to be feasible, usable, and non-labor-intensive intervention by the care staff. The obtained data suggested that the use of Wellness Nordic Relax ${ }^{\circledR}$ Chair provided short-term relief from aberrant motor behavior, agitation, apathy, depression, irritability, and night-time behavior disturbances, along with an increase in the quality of life of the person with dementia. The use of Wellness Nordic Relax ${ }^{\circledR}$ Chair may serve as a complementary tool to the nonpharmacological management techniques for people with dementia in nursing homes.

\section{Keywords}

Behavioral and psychological symptoms of dementia; BPSD; dementia care; people with dementia; rocking chair; single-case research study; quality of life

\section{Introduction}

Dementia is an increasingly prevalent chronic condition that affects an estimated 50 million people worldwide, with nearly 10 million new cases every year [1]. Since the prevalence of dementia is expected to increase substantially, it raises significant challenges to the healthcare and social-care systems [2]. People with dementia (PwD) experience a gradual, although progressive, loss of cognition, and more than $90 \%$ of these people ultimately develop behavioral and psychological symptoms of dementia (BPSD), also referred to as neuropsychiatric symptoms, during the trajectory of the disease [3]. BPSD is defined as the "signs and symptoms of disturbed behavior, mood, thought, or perception" [4]. BPSD may result in physical injuries and psychological distress in PWD and their family/caregivers, and is identified as a predictor of nursing home placement [5]. In nursing homes, verbal and physical abuse from the PwD exhibiting BPSD has been reported by care staff, which may result in minimized contact with the PWD, reducing their quality of care [4]. Consequently, it is required that effective management of BPSD is identified and applied.

Antipsychotic medication is commonly prescribed for BPSD, although it has been demonstrated to exhibit low efficacy and is associated with adverse effects, such as an increase in fall risk, cardiovascular events, mortality rate, and stroke occurrence [6, 7]. Therefore, first-line strategies for care should not unthinkingly include pharmacological interventions to avert or reduce the negative behavior, and should rather consider the person and their unique requirements. Consequently, a combination of pharmacological and non-pharmacological interventions is strongly recommended [8-11]. Recent systematic reviews have identified and reported the positive effects of various non-pharmacological interventions on the cognitive decline [12-14], $\operatorname{BPSD}[8,12-16]$, daily-life activities [12, 13, 17], and quality of life [12] with the intention to promote quality care, dignity, and safety for PwD. These non-pharmacological interventions exhibit varied positive effects on anxiety, depression, and agitated behavior. These interventions include physical activity, different forms of sensory-focused interventions such as music, aroma, massage, and light therapies, skills training and education in person-centered care for the care 
staff, and environmental redesigning [15]. Despite the extensive research on non-pharmacological interventions in dementia care, only a few studies have evaluated the use of rocking chairs in care for PwD [18, 19]. In a previous intervention study with a crossover design, Watson et al. [19] identified small reductions in anxiety $(p<0.03)$ and pain medication use $(p<0.01)$ using MannWhitney's test and Chi-squared test. In another single-case study, in which the participants served as their own controls, Snyder et al. [18] observed positive changes in the emotional states $(p<$ $0.05)$ and increased relaxation $(p<0.05)$.

Clearly, there is a dearth of recent evaluations on the use of rocking chairs in dementia care. Rocking chairs have been successfully used as an exercise tool to improve physical performance [20] and enhance cerebral perfusion [21] among older adults as well as for the treatment of adults with substance use disorders [22]. Non-pharmacological, sensory-focused approaches, aimed at supporting and offering alternative care and treatment to vulnerable populations such as PwD, require further evaluation. Care staff in dementia care is required to be well-informed so as to effectively plan appropriate interventions for dementia care. In this context, the present study was aimed to evaluate the use of a rocking chair in terms of BPSD, quality of life, and medication usage among PwD at individual level. The secondary aim of the present study was to describe the care staff's experiences of feasibility and usability of rocking chair in the care for PwD in a nursing home setting.

\section{Materials and Methods}

\subsection{Design}

A single-case research study (SCR) with an A-B-A design was conducted, in which the participants served as their own controls [23-25]. Phase A1 comprised a baseline/pre-intervention of three weeks. Phase B was an eight-week intervention with the use of Wellness Nordic Relax ${ }^{\circledR}$ Chair/ErgoNova Gungstolen ${ }^{\circledR}$ (Wellness Nordic, Humlebæk, Denmark/ErgoNova, Sundsvall, Sweden) [26] and phase A2 comprised the post-intervention, conducted two weeks after the completion of the intervention.

\subsection{Setting, Participants, and Recruitment}

The present study was conducted in an eight-unit nursing home in Sweden in the period between September, 2018 and January, 2019. In total, six female PwD and 11 care staff from three different dementia care units participated in the study. The demographic information of the PwD and care staff is summarized in Tables 1 and 2, respectively. The inclusion criteria for the PwD were a diagnosis of dementia and BPSD, while those for the care staff were to be a contact-person or possessing considerably good knowledge of the eligible PwD.

Eleven care staff informed the eight eligible PwD and their respective next of kin or trustees, both verbally and in writing, regarding the background and purpose of the study. They were also informed that the participation of the PWD was voluntary and that they could withdraw their participation if/whenever they wished to. Eight PwD commenced the study after their next of kin or trustees signed a statement that they did not oppose to the PwD's participation in the study (when possible, the PwD also signed that they did not oppose participation). Two PwD withdrew halfway into the study; one due to a severe worsening of her disease and the other due to 
unknown reasons underlying a repeated refusal to use the rocking chair. At the completion of the intervention, 11 care staff members were asked to participate in group interviews; nine care staff members participated after receiving verbal and written information regarding the interviews and signing the informed consent forms.

Table 1 Demographic data of the people with dementia (PwD).

\begin{tabular}{|c|c|c|c|c|}
\hline $\operatorname{PWD}(n=6)$ & Sex & Age (years) & $\begin{array}{l}\text { Time in nursing } \\
\text { home (months) }\end{array}$ & $\begin{array}{l}\text { Dementia diagnosis and } \\
\text { progression }\end{array}$ \\
\hline PwD 1 & $\mathrm{~F}$ & 89 & 10 & VaD, moderate \\
\hline PwD 2 & $\mathrm{~F}$ & 73 & 72 & $A D$, severe \\
\hline PwD 3 & $\mathrm{~F}$ & 77 & 33 & Unspecified, severe \\
\hline PwD 4 & $\mathrm{~F}$ & 85 & 24 & $A D$, severe \\
\hline PwD 5 & $\mathrm{~F}$ & 69 & 9 & VaD, mild \\
\hline PwD 6 & $\mathrm{~F}$ & 85 & 18 & $A D$, severe \\
\hline
\end{tabular}

PwD = People with dementia; F = Female $; A D=$ Alzheimer's disease $;$ VaD = Vascular disease dementia

Table 2 Demographic data of the care staff.

\begin{tabular}{ll}
\hline Care staff $(\mathbf{n}=\mathbf{1 1})$ & \\
\hline Sex (female/male) & $11 / 0$ \\
Median age in years (range) & $49(24-62)$ \\
Median years of experience at the current nursing home (range) & $8(3-8)$ \\
\hline
\end{tabular}

\subsection{Intervention}

\subsubsection{Content}

The Wellness Nordic Relax ${ }^{\circledR}$ Chair (Figure 1) is an electrically powered rocking chair made of artificial leather, with built-in music composed by Niels Eje [27, 28]. The chair has two built-in speakers in the lower part of the backrest, and the bass loop in the music generates tactile stimulation. The volume and bass are adjustable according to the individual. The chair runs three different programs: deep relaxation (Relax, $20 \mathrm{~min}$ ), recovery (Refresh, $20 \mathrm{~min}$ ), and gentle relaxation (Comfort, $2 \mathrm{~h}$ ). There is a footrest that can be raised and lowered, and the entire chair is on wheels for mobility. A 5-kg fiber blanket increases the feeling of security and relaxation [29], and a u-shaped pillow is also available for use. One rocking chair per care unit was placed in the central part of the unit, and privacy was assured by using curtains or shields. The 20-min Relax program was used in the present study. 


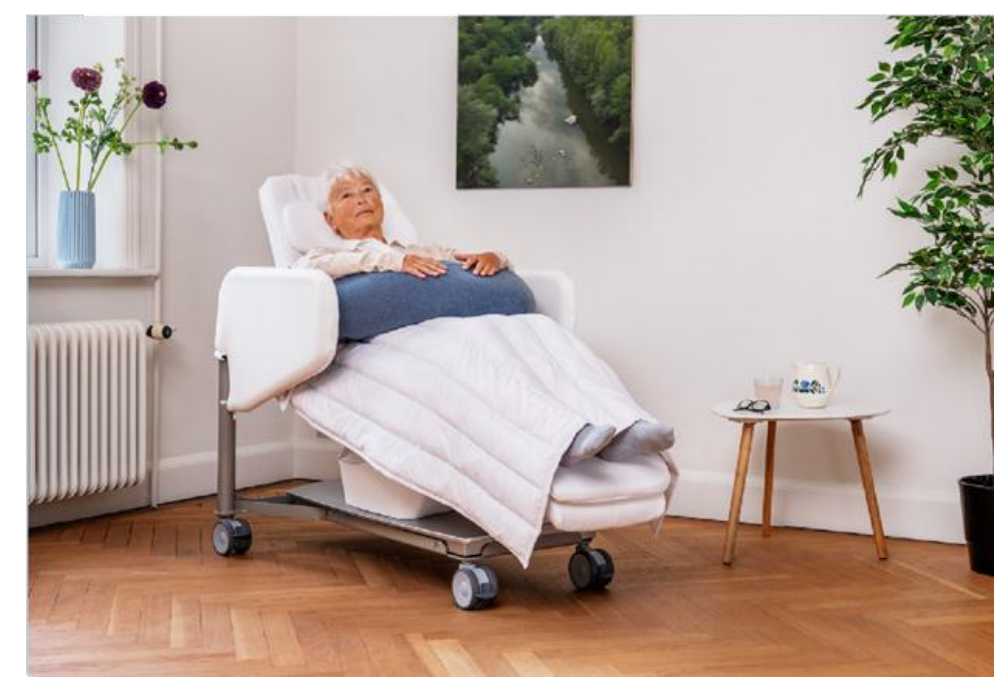

Figure 1 Wellness Nordic Relax ${ }^{\circledR}$ Chair/ErgoNova Gungstolen ${ }^{\circledR}$ (Wellness Nordic, Humlebæk, Denmark/ErgoNova, Sundsvall, Sweden).

\subsubsection{Delivery}

The intervention was performed for a total duration of eight weeks (study weeks: 4-11), in which six PwD used the Wellness Nordic Relax ${ }^{\circledR}$ Chair for a mean of five times/week (Table 3). In two of the dementia care units, PwD used the rocking chair during the weekdays, both during the daytime and in the evenings. In the third dementia care unit, the rocking chair was also used during the weekends and during night-time as well. The study was led by the first author, who provided support to and training of the care staff regarding the use of the rocking chair and the data collection on a weekly basis.

Table 3 Total number of times used or declined to use a rocking chair.

\begin{tabular}{lll}
\hline $\begin{array}{l}\text { Person with } \\
\text { dementia (PwD) }\end{array}$ & $\begin{array}{l}\text { Total number of times used a } \\
\text { rocking chair }\end{array}$ & $\begin{array}{l}\text { Total number of times } \\
\text { declined to use a rocking } \\
\text { chair }\end{array}$ \\
\hline PwD 1 & 24 & 13 \\
PwD 2 & 36 & 0 \\
PwD 3 & 41 & 8 \\
PwD 4 & 45 & 2 \\
PwD 5 & 43 & 0 \\
PwD 6 & 35 & 0 \\
\hline
\end{tabular}

Daily rocking chair sessions began with the care staff leading the PwD to the chair, suggesting them to lie down or sit on it. The PwD could also initiate the use of a rocking chair on their own, after that, the care staff would commence the program. Each PwD had their individualized schedule for when they used the rocking chair, which was mainly after lunch-time, although certain PwD preferred using it in the evenings before sleeping, while certain others used it during the night if experiencing difficulties in falling asleep. There were also differences among the care units regarding the presence of staff during the use of the rocking chair. One care unit had the 
care staff sitting next to the PwD during the use of a rocking chair, ensuring that the user was relaxed and comfortable. In the other two care units, staff first ensured that the PwD were comfortable and then remained nearby or placed a movement alarm next to the rocking chair.

\subsection{Data Collection}

The present SCR study comprised collecting quantitative and qualitative data pre-intervention (Phase A1), during the intervention (Phase B), and post-intervention (Phase A2). Table 4 presents an overview of the data collection.

Table 4 Overview of the data collection pre-intervention, intervention, and post-intervention.

\begin{tabular}{|c|c|c|c|c|c|c|c|c|c|c|c|c|c|c|c|c|c|c|c|}
\hline & \multicolumn{9}{|c|}{ Pre-intervention } & \multicolumn{8}{|c|}{ Intervention } & \multicolumn{2}{|c|}{$\begin{array}{c}\text { Post- } \\
\text { interven } \\
\text { tion }\end{array}$} \\
\hline Study weeks & \multicolumn{3}{|c|}{1} & \multicolumn{3}{|c|}{2} & \multicolumn{3}{|c|}{3} & 4 & 5 & 6 & 7 & 8 & 9 & 10 & 11 & 12 & 13 \\
\hline Demographic data & \multicolumn{3}{|c|}{$x$} & \multirow[b]{2}{*}{$x$} & \multirow[b]{2}{*}{$\mathrm{x}$} & \multirow{2}{*}{\multicolumn{2}{|c|}{$x$}} & \multirow[b]{2}{*}{$\mathrm{x}$} & \multirow[b]{2}{*}{$\mathrm{x}$} & \multirow[b]{2}{*}{$x$} & & \multirow[b]{2}{*}{$x$} & & \multirow[b]{2}{*}{$x$} & & & \multirow[b]{2}{*}{$x$} & & $x$ \\
\hline BPSD (NPI-NH) & $x$ & $\mathrm{x}$ & $\mathrm{x}$ & & & & & & & & & & & & & & & & $x$ \\
\hline QUALID & $x$ & $\mathrm{x}$ & $\mathrm{x}$ & $x$ & $\mathrm{x}$ & $x$ & $\mathrm{x}$ & $x$ & $x$ & $x$ & & $x$ & & $x$ & & & $x$ & & $x$ \\
\hline Medication usage & & $x$ & & & $x$ & & & $x$ & & $x$ & $x$ & $x$ & $x$ & $x$ & $\mathrm{x}$ & $x$ & $x$ & $x$ & $x$ \\
\hline Care staff's notes & & & & & & & & & & $x$ & $x$ & $x$ & $x$ & $x$ & $\mathrm{x}$ & $x$ & $x$ & & \\
\hline $\begin{array}{l}\text { Group interviews with } \\
\text { care staff }\end{array}$ & & & & & & & & & & & & & & & & & & & $x$ \\
\hline
\end{tabular}

BPSD = Behavioral and psychological symptoms of dementia, NPI-NH = Neuropsychiatric Inventory - Nursing Home, QUALID = Quality of Life in Late-stage Dementia

\subsubsection{Assessment Instruments, Medication Usage, and Notes}

Neuropsychiatric Inventory-Nursing Home (NPI-NH) scale [30, 31] was used by the care staff for assessing the PwD's BPSD (dependent variables), pre-intervention, during the intervention, and post-intervention. The NPI-NH comprises 12 items, including the following neuropsychiatric symptoms: delusions, hallucinations, agitation, depression, anxiety, euphoria, apathy, disinhibition, irritability, aberrant motor behavior (restlessness and wandering), night-time behavior (sleep) disturbances, and appetite and eating disorders; for each of these 12 items, the presence, frequency, and severity were assessed, and the score for each neuropsychiatric symptom was obtained by multiplying the severity (range: $1-3$ ) by the frequency (range: 1-4). The summed symptom scores provided the total NPI score, which ranged from 0 to 144 . The NPI-NH data were collected three times/week during the three-week pre-intervention, once biweekly during the eight-week intervention, and once during the two-week post-intervention.

The Quality of Life in Late-stage Dementia (QUALID) scale [32, 33] was used by the care staff for assessing the PwD's quality of life (dependent variables) pre-intervention, during the intervention, and post-intervention. QUALID comprises 11 items, including the following behaviors: smiling, 
sadness, crying, emotional discomfort, physical discomfort, discontent, irritability/aggression, appetite, enjoying physical contact, enjoying social contact, and appearing calm and relaxed. The 11 statements were ranked on a five-point scale. The summed scores ranged from 11 to 55, with lower scores representing a higher quality of life. QUALID data were collected three times/week during the three-week pre-intervention, once biweekly during the eight-week intervention, and once during the two-week post-intervention.

PwD's medication usage was collected weekly pre-intervention, during the intervention, and post-intervention. Care staff's notes, written in conjunction with each time the PwD used the Wellness Nordic Relax ${ }^{\circledR}$ Chair, which included observations of the PwD's reactions and opinions, both verbal and non-verbal, were collected during the eight-week intervention.

\subsubsection{Group Interviews}

Group interviews were conducted post-intervention to explore the overall experiences of the care staff regarding the use of Wellness Nordic Relax ${ }^{\circledR}$ Chair in their care for PwD. A semistructured interview guide (Table 5) was utilized, which comprises a set of open-ended questions in the beginning, followed by targeted questions [34]. Follow-up and probing questions were included for clarification when required. Three group interviews were conducted with nine care staff members within their respective care units, with each interview lasting for 16-22 min. All the interviews were recorded digitally and transcribed verbatim.

Table 5 Interview guide for group interviews with care staff.

What was your overall experience of using the rocking chair in the care of PwD? Has the use of a rocking chair contributed to a change in the PWD's BPSD, and if so, how? Has the use of a rocking chair contributed to a change in the PWD's quality of life, and if so, how? In what situations (how, when, and why) did you choose to use a rocking chair: at a certain time of day, during specific BPSD in the PwD, or for some other reason?

Did you encounter specific difficulties in using a rocking chair, and if so, what were they?

How did you perceive the feasibility of using a rocking chair?

What are your thoughts about eventual future use of a rocking chair?

PwD = People with dementia; BPSD = Behavioral and psychological symptoms of dementia

\subsection{Data Analyses}

Quantitative data were analyzed through visual inspection and descriptive statistics. Visual inspection included the calculation of each participant's performance, which was graphed to visually determine the (1) trend or progress over time, (2) level or magnitude, and (3) variability vs. stability of the data [23]. The visual inspection procedure followed the steps outlined by Lane and Gast [35] using the graphic display and the split-middle method of dividing the data into withincondition and between-condition data analyses. Stability was defined as $80 \%$ of the data points being within $\pm 25 \%$ of the phase median. Qualitative data were summarized in correspondence to the questions in the interview guide using qualitative content analysis with a descriptive approach [34]. The qualitative description was used to present the variations in the experiences of care staff regarding the use of a rocking chair in the care for PwD. 


\subsection{Ethical Considerations}

The present study was approved by the Regional Ethical Review Board in Uppsala (D no. 2018/301), and conformed to the principles outlined in the Declaration of Helsinki [36] and in the Recommendations for the Protection of Research Participants by the International Committee of Medical Journal Editors' (ICMJE) [37].

\section{Results}

An overview of the results obtained for the BPSD and quality of life of the six PWD is presented in Table 6. The detailed results and the respective graphs for each of the six cases are presented in Section 3.1, while Section 3.2 describes the findings from the group interviews.

Table 6 Overview of PwD's BPSD and quality of life.

\begin{tabular}{|c|c|c|c|c|}
\hline PwD & No presence of BPSD & $\begin{array}{l}\text { Worsening } \\
\text { or no improvement } \\
\text { of BPSD and/or } \\
\text { quality of life }\end{array}$ & $\begin{array}{l}\text { Improvement of } \\
\text { BPSD and/or quality } \\
\text { of life }\end{array}$ & $\begin{array}{l}\text { Number of BPSD, } \\
\text { and/or quality of } \\
\text { life, showing } \\
\text { improvement }\end{array}$ \\
\hline 1 & $\begin{array}{l}\text { Agitation } \\
\text { Anxiety } \\
\text { Euphoria } \\
\text { Apathy } \\
\text { Disinhibition } \\
\text { Irritability } \\
\text { Aberrant motor } \\
\text { behavior } \\
\text { Night-time behavior } \\
\text { disturbances } \\
\text { Appetite and eating } \\
\text { disorders }\end{array}$ & $\begin{array}{l}\text { Delusions } \\
\text { Hallucinations } \\
\text { Quality of life }\end{array}$ & Depression & $1 / 13$ \\
\hline 2 & $\begin{array}{l}\text { Delusions } \\
\text { Hallucinations } \\
\text { Agitation } \\
\text { Depression } \\
\text { Anxiety } \\
\text { Euphoria } \\
\text { Apathy } \\
\text { Disinhibition } \\
\text { Appetite and eating } \\
\text { disorders }\end{array}$ & Irritability & $\begin{array}{l}\text { Aberrant motor } \\
\text { behavior } \\
\text { Night-time behavior } \\
\text { disturbances } \\
\text { Quality of life }\end{array}$ & $3 / 13$ \\
\hline 3 & $\begin{array}{l}\text { Delusions } \\
\text { Hallucinations } \\
\text { Agitation } \\
\text { Depression }\end{array}$ & $\begin{array}{l}\text { Anxiety } \\
\text { Quality of life }\end{array}$ & Apathy & $1 / 13$ \\
\hline
\end{tabular}




\begin{tabular}{|c|c|c|c|c|}
\hline & $\begin{array}{l}\text { Euphoria } \\
\text { Disinhibition } \\
\text { Irritability } \\
\text { Aberrant motor } \\
\text { behavior } \\
\text { Night-time behavior } \\
\text { disturbances } \\
\text { Appetite and eating } \\
\text { disorders }\end{array}$ & & & \\
\hline 4 & $\begin{array}{l}\text { Delusions } \\
\text { Hallucinations } \\
\text { Euphoria } \\
\text { Disinhibition } \\
\text { Night-time behavior } \\
\text { disturbances } \\
\text { Appetite and eating } \\
\text { disorders }\end{array}$ & $\begin{array}{l}\text { Agitation } \\
\text { Depression } \\
\text { Anxiety } \\
\text { Quality of life }\end{array}$ & $\begin{array}{l}\text { Apathy } \\
\text { Irritability } \\
\text { Aberrant motor } \\
\text { behavior }\end{array}$ & $3 / 13$ \\
\hline 5 & $\begin{array}{l}\text { Delusions } \\
\text { Hallucinations } \\
\text { Agitation } \\
\text { Anxiety } \\
\text { Euphoria } \\
\text { Apathy } \\
\text { Disinhibition } \\
\text { Irritability } \\
\text { Aberrant motor } \\
\text { behavior } \\
\text { Night-time behavior } \\
\text { disturbances } \\
\text { Appetite and eating } \\
\text { disorders }\end{array}$ & & $\begin{array}{l}\text { Depression } \\
\text { Quality of life }\end{array}$ & $2 / 13$ \\
\hline 6 & $\begin{array}{l}\text { Delusions } \\
\text { Hallucinations } \\
\text { Depression } \\
\text { Anxiety } \\
\text { Euphoria } \\
\text { Disinhibition } \\
\text { Night-time behavior } \\
\text { disturbances } \\
\text { Appetite and eating } \\
\text { disorders }\end{array}$ & & $\begin{array}{l}\text { Agitation } \\
\text { Apathy } \\
\text { Irritability } \\
\text { Aberrant motor } \\
\text { behavior } \\
\text { Quality of life }\end{array}$ & $5 / 13$ \\
\hline
\end{tabular}

$\mathrm{PwD}=$ People with dementia; BPSD = Behavioral and psychological symptoms of dementia 


\subsection{PwD's BPSD, Quality of Life, and Medication Usage}

\subsubsection{PwD 1}

There was an assessed presence of and change in BPSD in terms of delusions, hallucinations, and depression, along with an assessed change in the quality of life (Figure 2). The split-middle method for trend estimation indicated a decelerating trend for delusions and hallucinations and an accelerating trend for depression and quality of life during the pre-intervention. During the intervention, an accelerating trend for delusions, hallucinations, and quality of life and a zerocelerating trend for depression were observed. Mean, median, and relative change measures indicated a decrease in the symptoms of depression, an increase in the symptoms of delusions and hallucinations, and a decreased quality of life from pre-intervention to intervention. Data for delusions, hallucinations, and quality of life were stable, while the data for depression were variable during both pre-intervention and intervention. There was no medication usage during the study. Care staff described, through notes and in the group interviews, that Wellness Nordic Relax ${ }^{\circledR}$ Chair was used when the person was feeling restless and disheartened, usually after lunchtime. Besides the times when the person refused to rock, "... she would be in such a bad mood, so on certain days it just did not work", generally the use of rocking chair assisted the person in relaxing and becoming calmer.

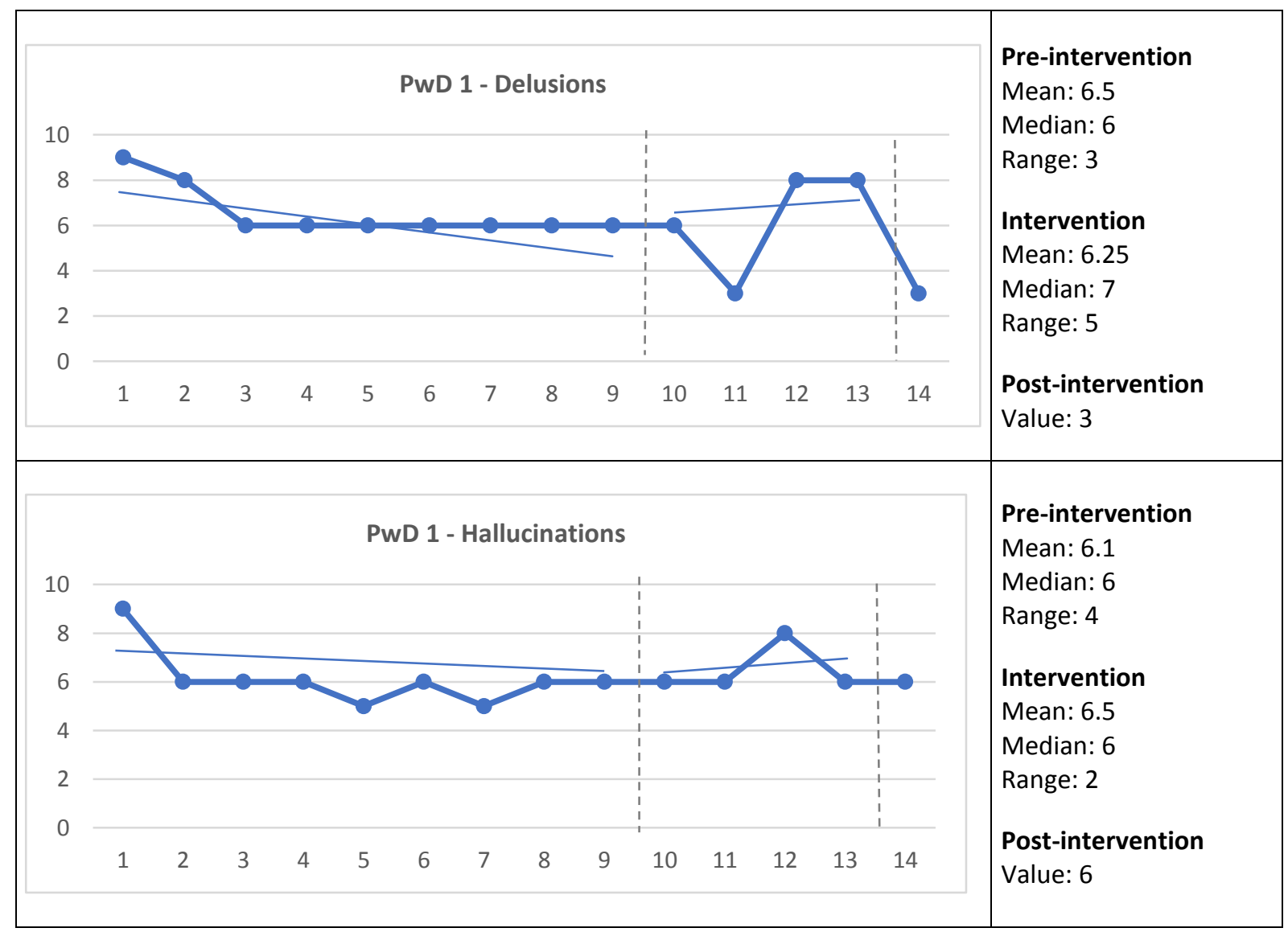




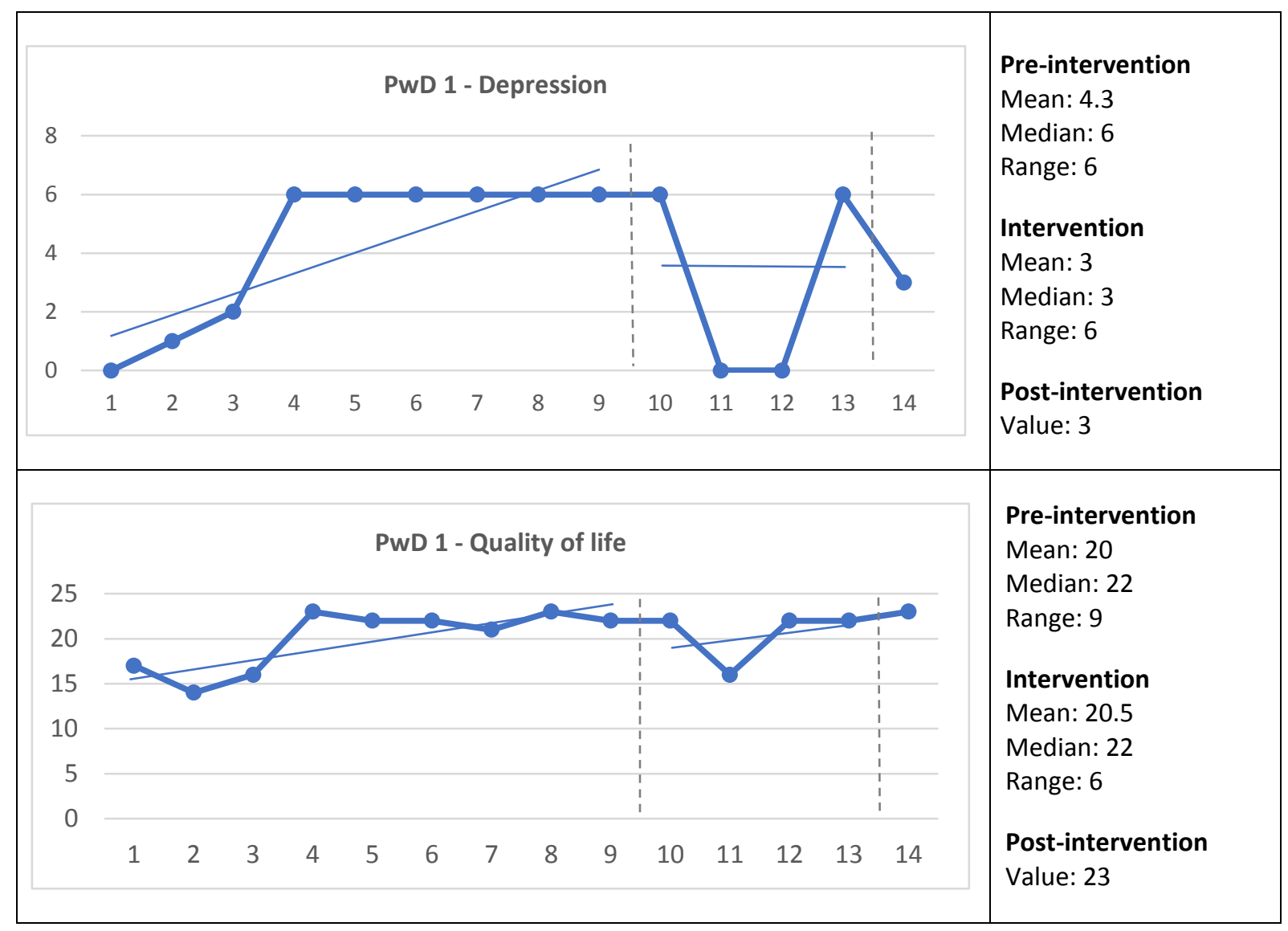

Figure 2 Care staff assessed the presence and change in the behavioral and psychological symptoms of dementia (BPSD) and quality of life. The $Y$-axes show the scores for the respective BPSD or quality of life, and the $X$-axes show measurement points: 1-9 = three weeks pre-intervention, 10-13 = four weeks intervention, $14=$ oneweek post-intervention, see also vertical dashed lines. Horizontal lines represent trend lines for pre-intervention and intervention. PwD = Person with dementia.

\subsubsection{PwD 2}

There was an assessed presence of and change in BPSD in terms of irritability, aberrant motor behavior, and night-time behavior disturbances, along with an assessed change in the quality of life (Figure 3). The split-middle method for trend estimation indicated a zero-celerating trend for irritability, a decelerating trend for aberrant motor behavior and night-time behavior disturbances, and an accelerating trend for quality of life during the pre-intervention. During the intervention, an accelerating trend for irritability, a decelerating trend for aberrant motor behavior, and a zerocelerating trend for night-time behavior disturbances and quality of life was observed. Mean, median, and relative change measures indicated an increase in the symptoms of irritability, a decrease in the symptoms of aberrant motor behavior and night-time behavior disturbances, and an increased quality of life from pre-intervention to intervention. Data for irritability, aberrant motor behavior, and quality of life were stable during both pre-intervention and intervention, while the data for night-time behavior disturbances were variable. There was no change in medication usage during the study. In notes and group interviews, care staff described that Wellness Nordic Relax ${ }^{\circledR}$ Chair was used regularly after lunch-time. The person never refused to 
rock, and besides certain times when the person became impatient while rocking, "Are we not done yet?", it was relaxing for her.

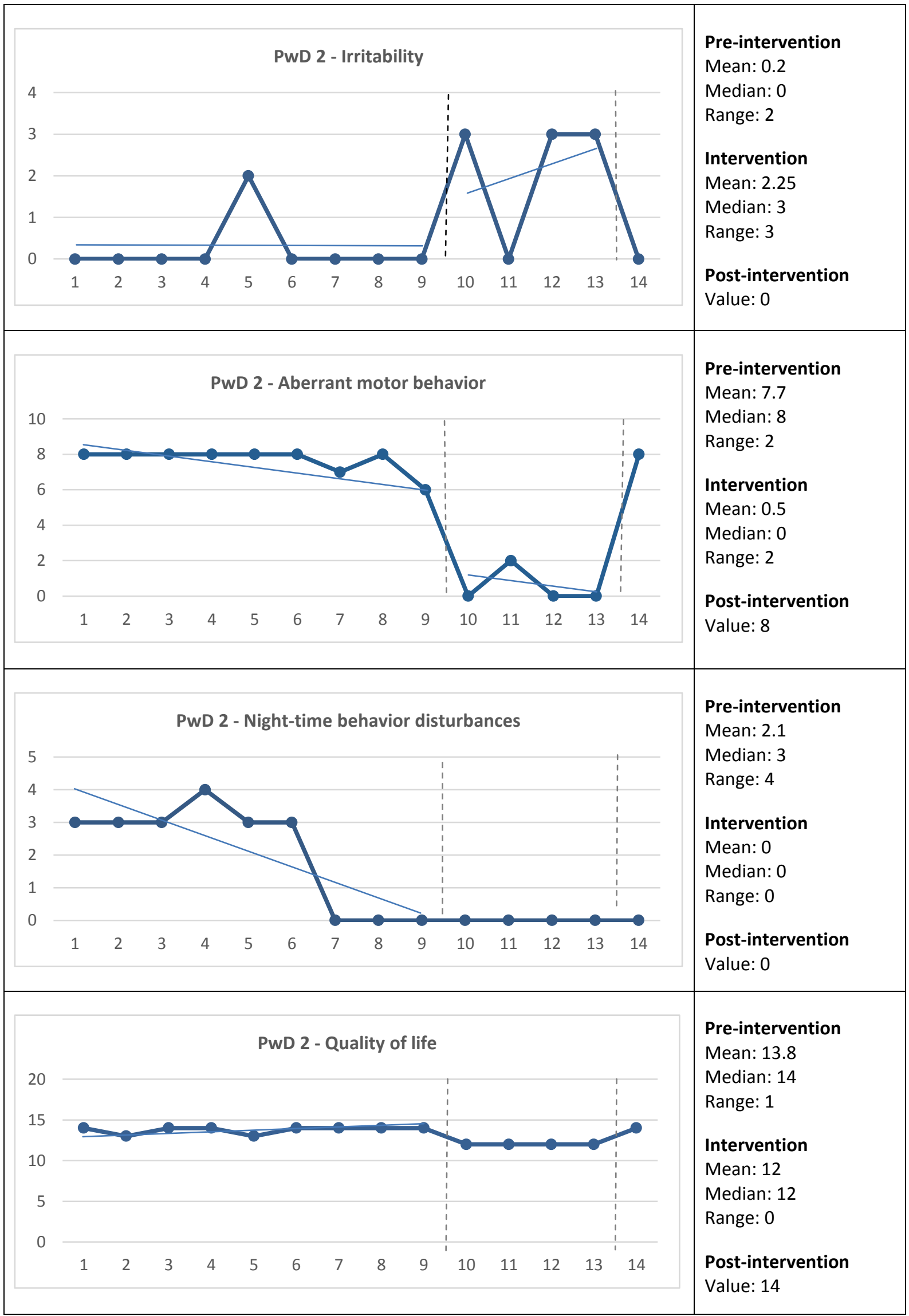


Figure 3 Care staff assessed the presence and change in the behavioral and psychological symptoms of dementia (BPSD) and quality of life. The $Y$-axes show the scores for the respective BPSD or quality of life, and the $X$-axes show measurement points: 1-9 = three weeks pre-intervention, 10-13 = four weeks intervention, $14=$ oneweek post-intervention, see also vertical dashed lines. Horizontal lines represent trend lines for pre-intervention and intervention. PwD = Person with dementia.

\subsubsection{PwD 3}

There was an assessed presence of and change in BPSD in terms of anxiety and apathy, along with an assessed change in the quality of life (Figure 4). The split-middle method for trend estimation indicated an accelerating trend for anxiety, a decelerating trend for apathy, and a zerocelerating trend for quality of life during the pre-intervention. During the intervention, a zerocelerating trend for anxiety and apathy and an accelerating trend for quality of life was observed. Mean, median, and relative change measures indicated an increase in the symptoms of anxiety, a decrease in the symptoms of apathy, and a decreased quality of life from pre-intervention to postintervention. The data for anxiety and quality of life were stable during both pre-intervention and intervention, while the data for apathy were variable during the pre-intervention and stable during the intervention. There was no change in medication usage during the study. In notes and group interviews, the care staff described that Wellness Nordic Relax ${ }^{\circledR}$ Chair was used when the person was anxious. On certain days, the person became scared and angry because of the movements of the chair, fearing that she would fall out of it; therefore, she would request to get up or sit up rather than lying in the chair. She would also feel disturbed by the sounds of others moving or talking close-by. On the other days, she enjoyed the rocking, and would say that "it was wonderful and that she could not have asked for a better time than this." Often, she would fall asleep in the chair; therefore, the care staff would let her rock prior to lunch-time rather than in the afternoon so that her night-time sleep schedule would remain undisturbed.

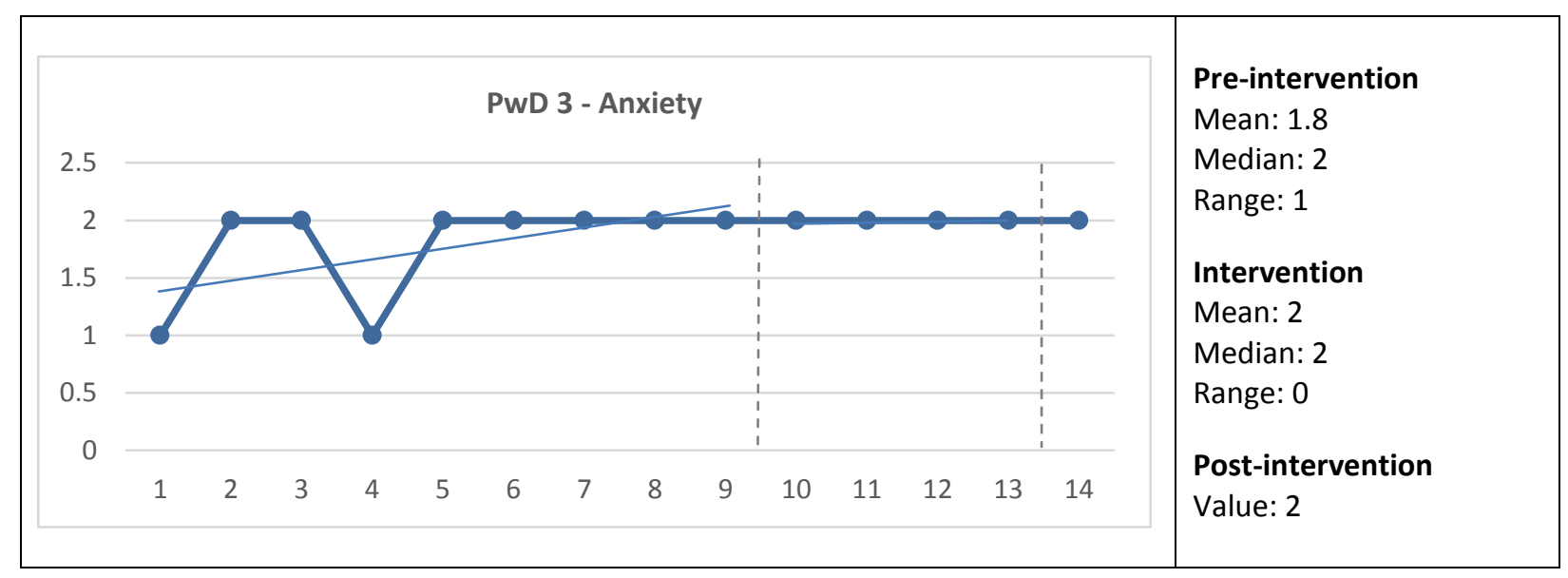




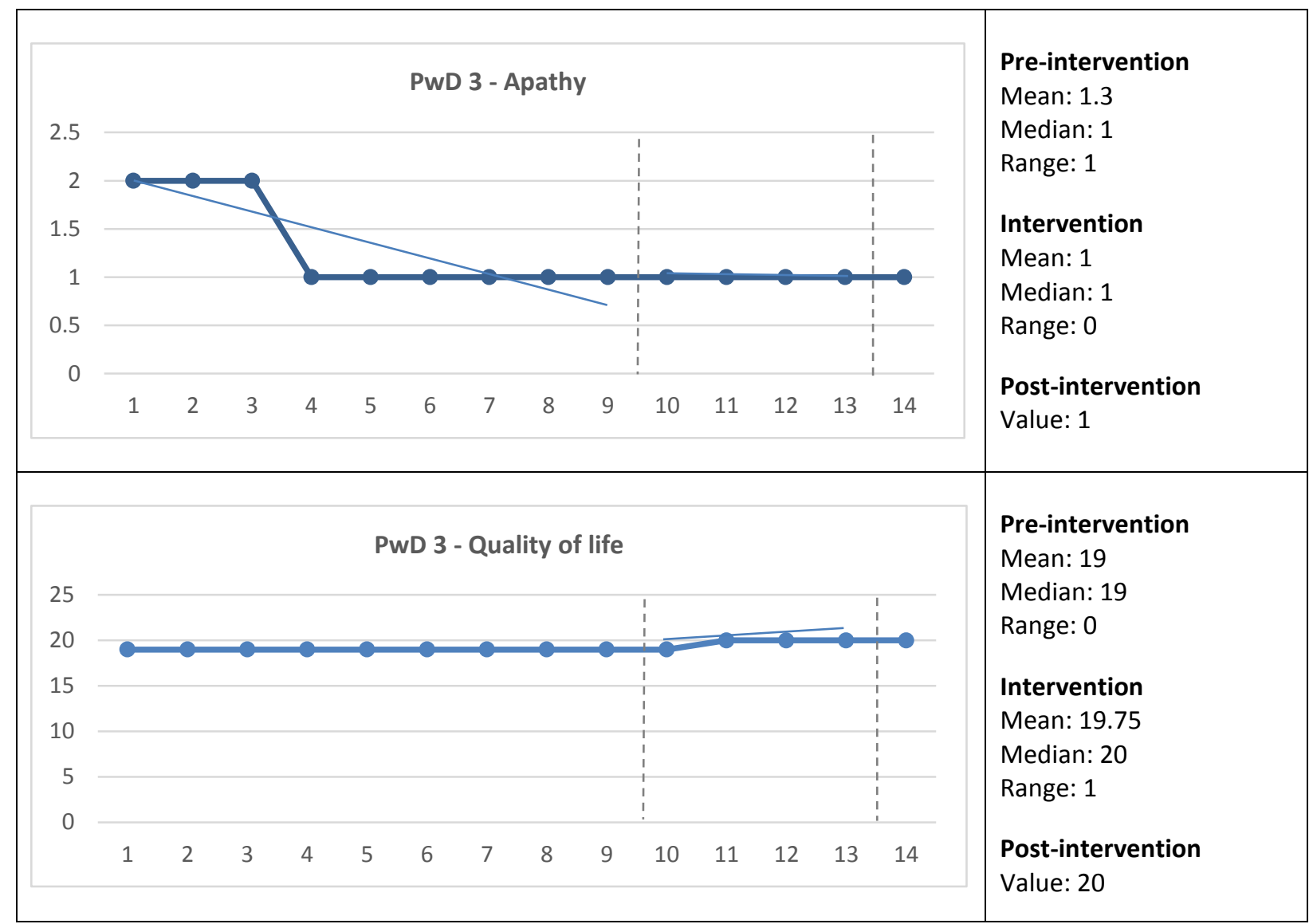

Figure 4 Care staff assessed the presence and change in the behavioral and psychological symptoms of dementia (BPSD) and quality of life. The $Y$-axes show the scores for the respective BPSD or quality of life, and the $X$-axes show measurement points: 1-9 = three weeks pre-intervention, 10-13 = four weeks intervention, $14=$ oneweek post-intervention, see also vertical dashed lines. Horizontal lines represent trend lines for pre-intervention and intervention. PwD = Person with dementia.

\subsubsection{PwD 4}

There was an assessed presence of and change in BPSD in terms of agitation, depression, anxiety, apathy, irritability, and aberrant motor behavior, along with an assessed change in the quality of life (Figure 5). The split-middle method for trend estimation indicated an accelerating trend for agitation, anxiety, apathy, irritability, aberrant motor behavior, and quality of life, and a zero-celerating trend for depression during the pre-intervention. During the intervention, a decelerating trend for agitation, depression, apathy, irritability, aberrant motor behavior, and quality of life and an accelerating trend for anxiety was observed. Mean, median, and relative change measures indicated an increase in the symptoms of agitation, depression, and anxiety, a decrease in the symptoms of apathy, irritability, and aberrant motor behavior, and a decreased quality of life, from pre-intervention to post-intervention. Data were variable for agitation, depression, anxiety, and aberrant motor behavior, while the data for apathy, irritability, and quality of life were stable during the pre-intervention. The data for depression, anxiety, and irritability were variable, while the data for agitation, apathy, aberrant motor behavior, and quality of life were stable during the intervention. The PwD's usage of antidepressants was terminated in 
the intervention Week 10,11 , and 12 , while in Week 10 , the medication for urinary tract infection was used temporarily. In the notes and group interviews, the care staff described that Wellness Nordic Relax ${ }^{\circledR}$ Chair was used when the person wandered around restlessly and was in an irritable mood, or when she, on her own initiative, walked up to the chair and stated in the following words: "I want to lie down now; this is my bed here." Although she remained restless afterward, her irritable mood almost always changed into a more relaxed mood after the rocking.

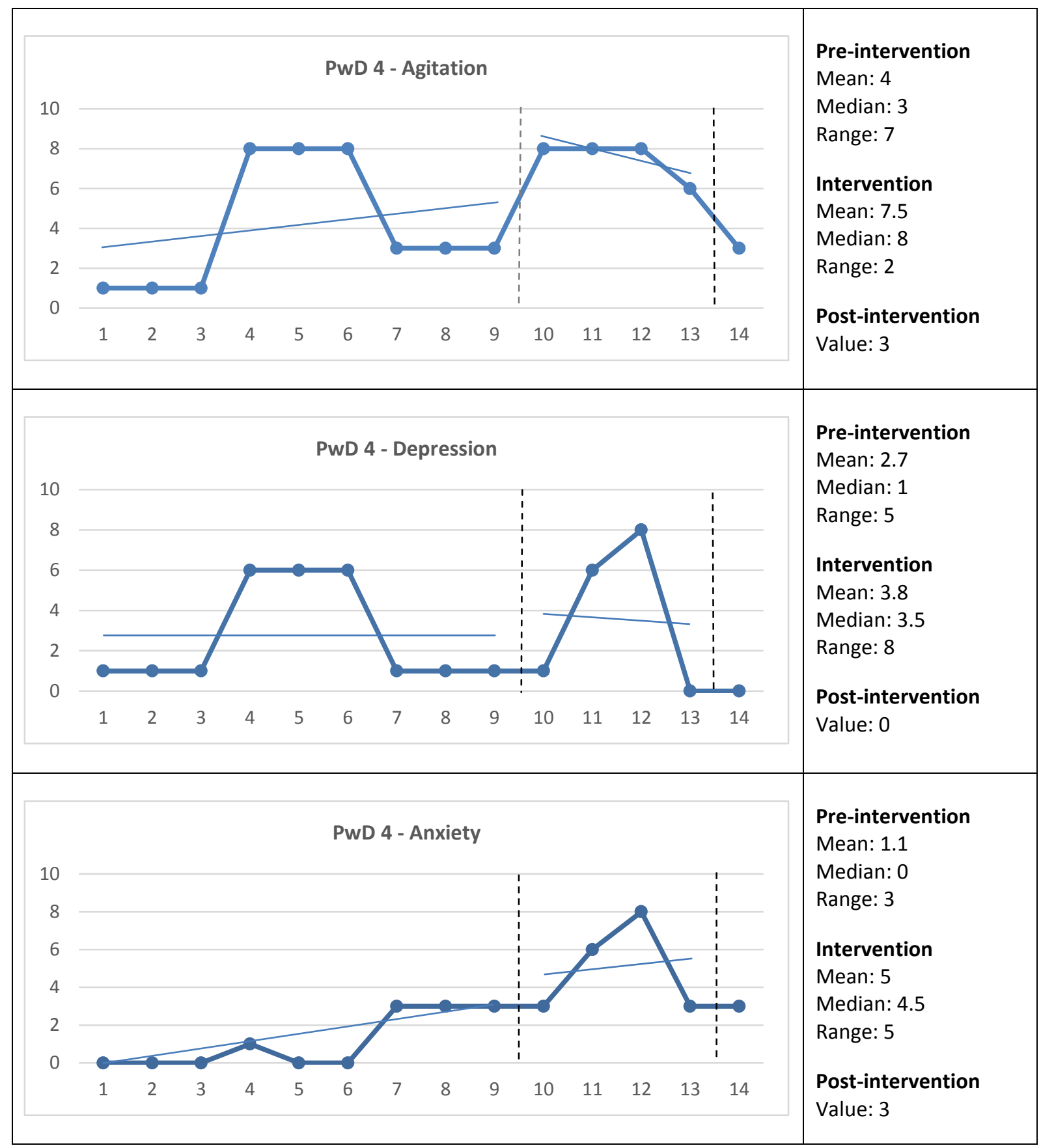




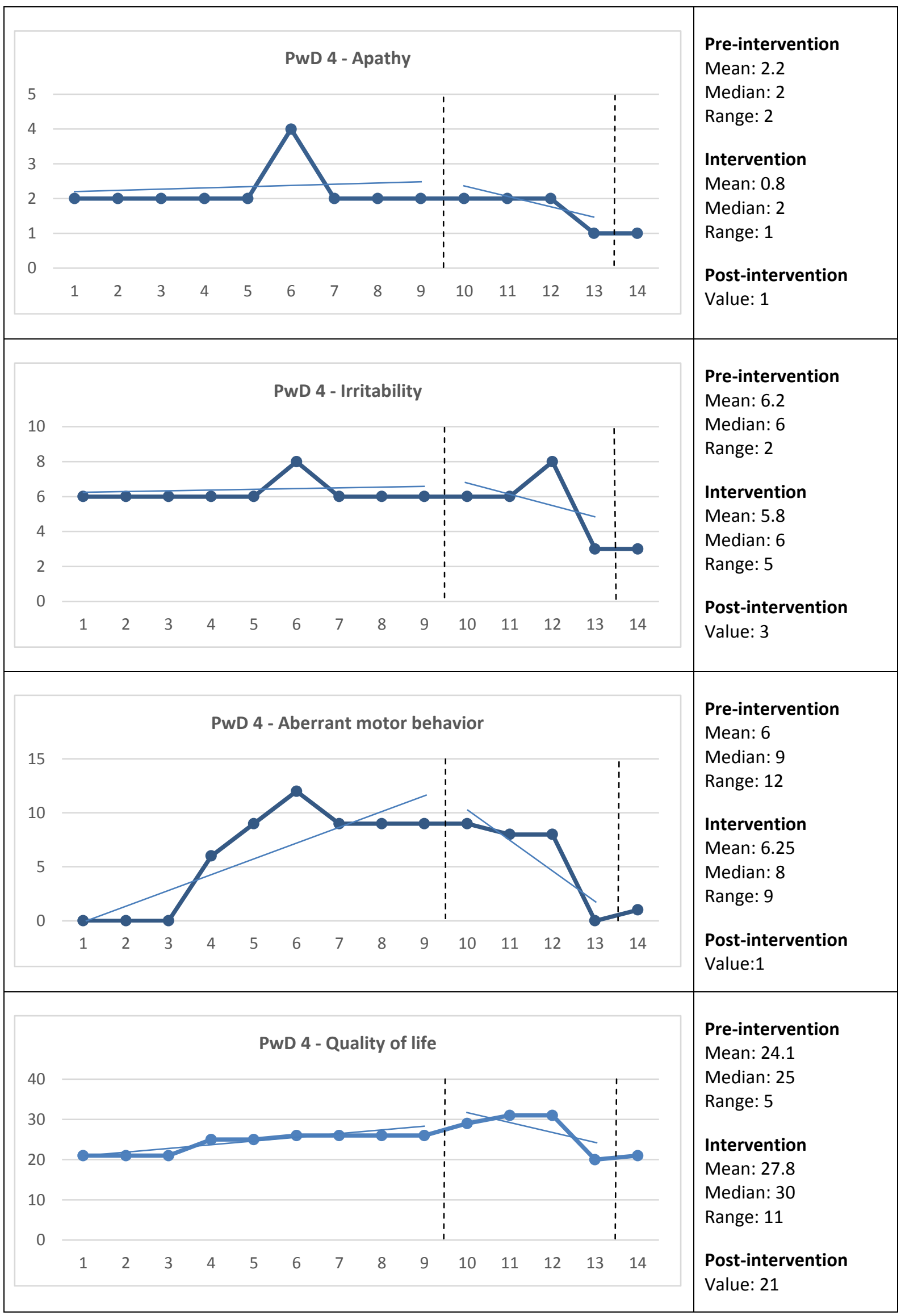


Figure 5 Care staff assessed the presence and change in the behavioral and psychological symptoms of dementia (BPSD) and quality of life. The $Y$-axes show the scores for the respective BPSD or quality of life, and the $X$-axes show measurement points: 1-9 = three weeks pre-intervention, 10-13 = four weeks intervention, 14 = oneweek post-intervention, see also vertical dashed lines. Horizontal lines represent trend lines for pre-intervention and intervention. PwD = Person with dementia.

\subsubsection{PwD 5}

There was an assessed presence of and change in BPSD in terms of depression, along with an assessed change in the quality of life (Figure 6). The split-middle method for trend estimation indicated a zero-celerating trend for depression and quality of life during the pre-intervention and intervention. Mean, median, and relative change measures indicated a decrease in the symptoms of depression and an increase in the quality of life from pre-intervention to post-intervention. The data for depression and quality of life were stable during both pre-intervention and intervention. There was no medication usage during the study. In the notes and group interviews, the care staff described that Wellness Nordic Relax ${ }^{\circledR}$ Chair was used whenever the person desired it, "She rocked in the chair post breakfast; afterward, she would say it was enjoyable and thought she fell asleep for a while."

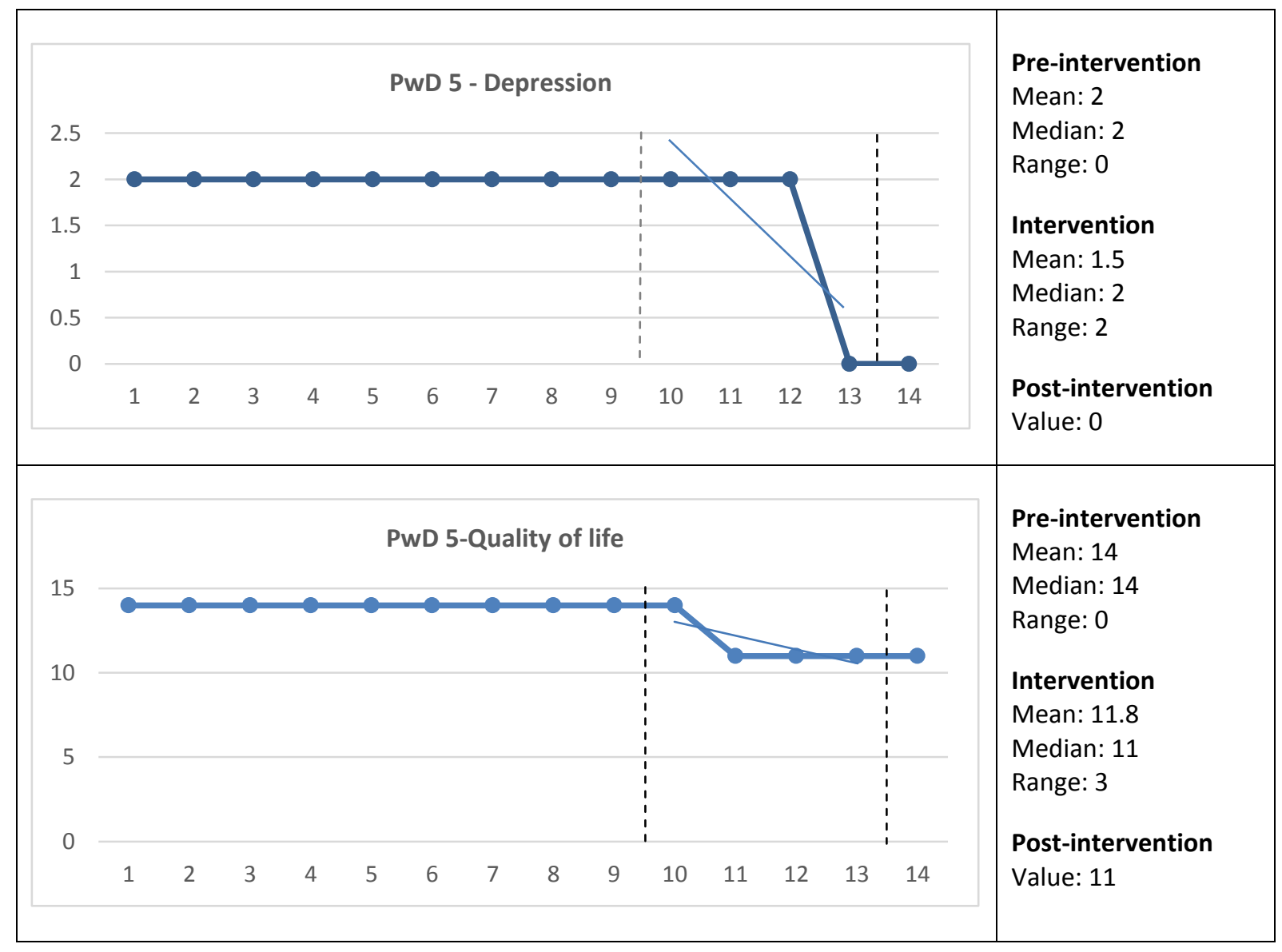


Figure 6 Care staff assessed the presence and change in the behavioral and psychological symptoms of dementia (BPSD) and quality of life. The $Y$-axes show the scores for the respective BPSD or quality of life, and the $X$-axes show measurement points: 1-9 = three weeks pre-intervention, 10-13 = four weeks intervention, $14=$ oneweek post-intervention, see also vertical dashed lines. Horizontal lines represent trend lines for pre-intervention and intervention. PwD = Person with dementia.

\subsubsection{PwD 6}

There was an assessed presence of and change in BPSD in terms of agitation, apathy, irritability, and aberrant motor behavior, along with an assessed change in the quality of life (Figure 7). The split-middle method for trend estimation indicated a decelerating trend for agitation, irritability, and aberrant motor behavior and an accelerating trend for apathy and quality of life during the pre-intervention. During the intervention, a zero-celerating trend for agitation and apathy, an accelerating trend for irritability and quality of life, and a decelerating trend for aberrant motor behavior were observed. Mean, median, and relative change measures indicated a decrease in the symptoms of agitation, apathy, irritability, aberrant motor behavior, and increased quality of life, from pre-intervention to post-intervention. The data for agitation, apathy, irritability, and aberrant motor behavior were variable, while the data for quality of life were stable during the preintervention. The data for agitation, apathy, irritability, and quality of life were stable, and the data for aberrant motor behavior were variable during the intervention. There was no medication usage during the study. In notes and group interviews, the care staff described that Wellness Nordic Relax ${ }^{\circledR}$ Chair was used when the person was restless and irritable, as stated in the following words: "We would walk with her to her bed, and she would lie down, although she would get up immediately. Then we would walk with her to the rocking chair, where she would express her wish to lie down. I think she finds it cozy, peaceful, and quiet, there in the corner, with no one to disturb her."

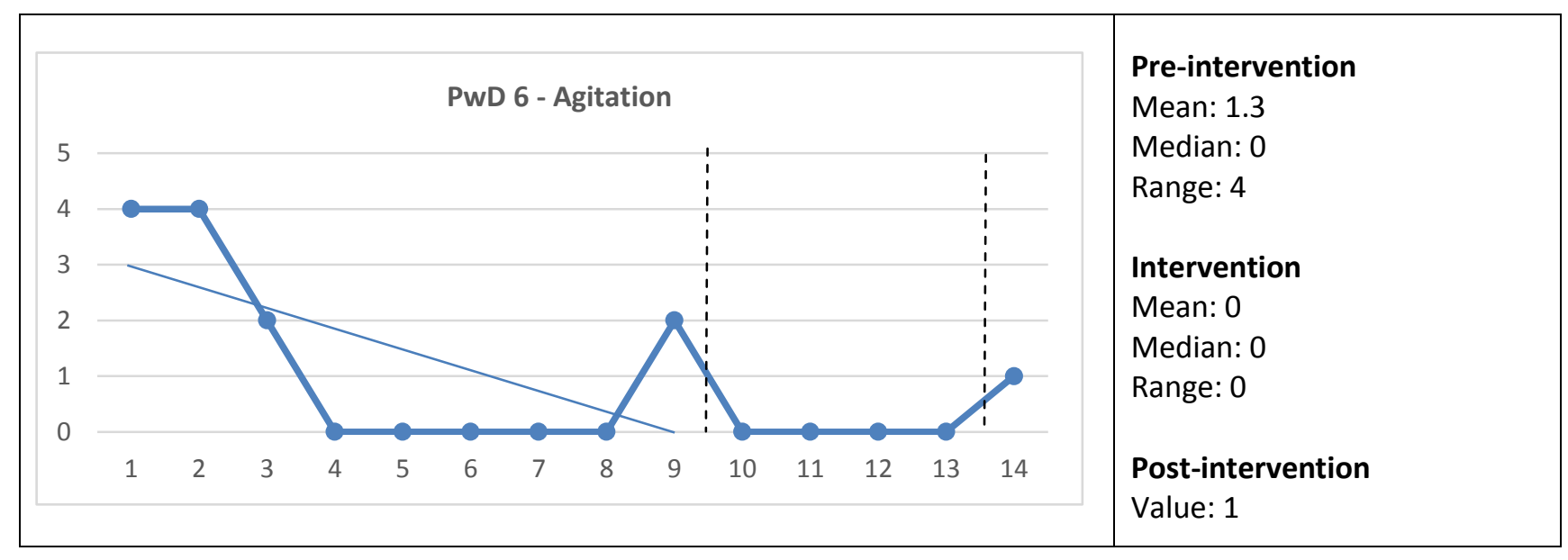




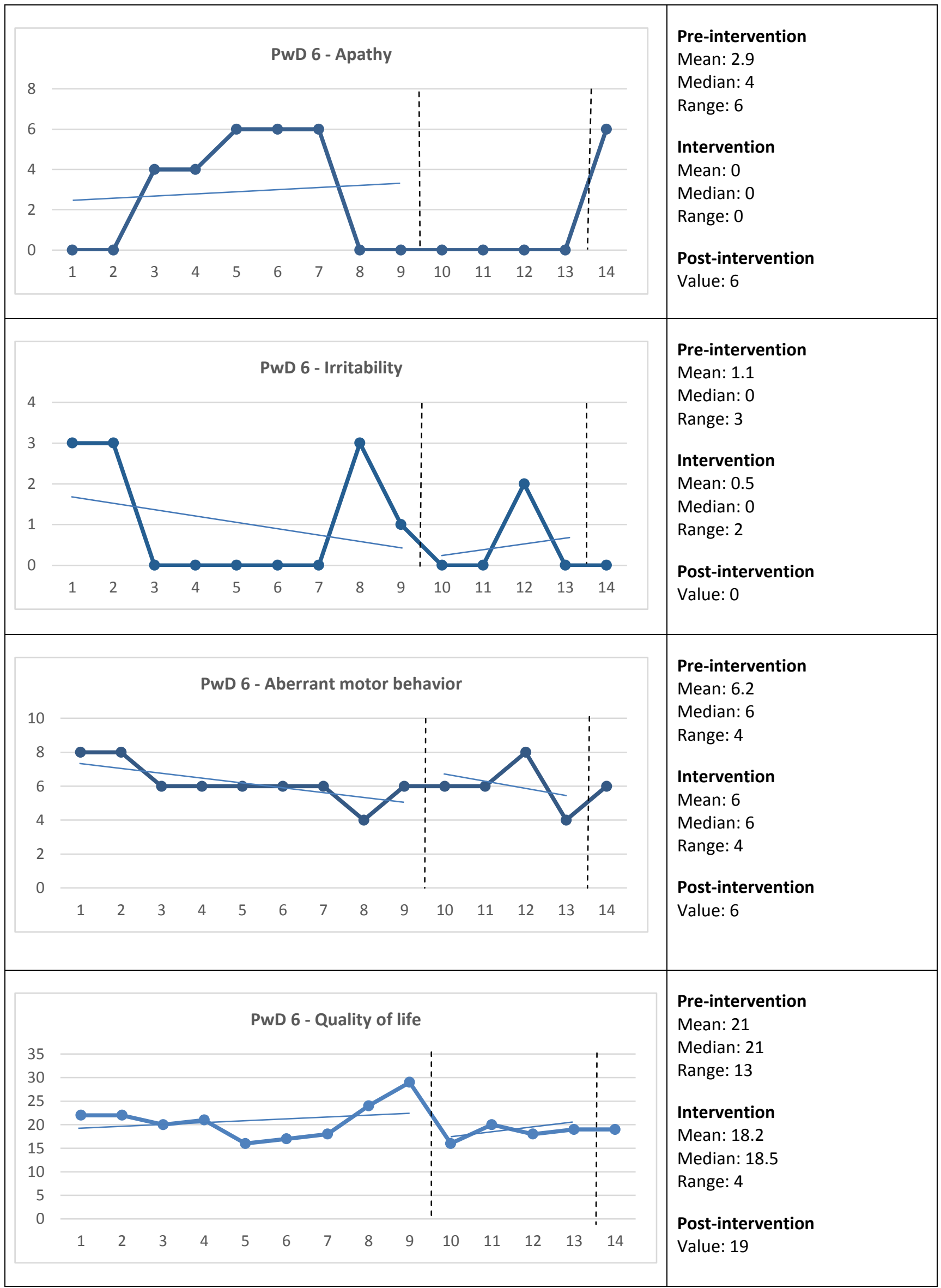


Figure 7 Care staff assessed the presence and change in the behavioral and psychological symptoms of dementia (BPSD) and quality of life. The $Y$-axes show the scores for the respective BPSD or quality of life, and the $X$-axes show measurement points: 1-9 = three weeks pre-intervention, 10-13 = four weeks intervention, $14=$ oneweek post-intervention, see also vertical dashed lines. Horizontal lines represent trend lines for pre-intervention and intervention. PwD = Person with dementia.

\subsection{Care Staff's Experiences regarding the Feasibility and Usability of Wellness Nordic Relax ${ }^{\circledR}$ Chair}

As the use of Wellness Nordic Relax ${ }^{\circledR}$ Chair immediately became a routine and regular intervention for the persons' BPSD, it was regarded as both feasible and of use in the care for PwD. The feasibility was facilitated as the care staff shared joint responsibility for the PwD. In the study, when there were queries, the care staff members supported each other. The care staff felt that the allocation of sufficient time was vital for the feasibility of the study, as it would require time for the person to be able to relax in the chair, and until then, it was required that the care staff stayed with the person. When the PwD appeared relaxed, the care staff felt it to be safe to either guard them at a distance or use a motion alarm placed next to the rocking chair.

Unanimously, the care staff stated the requirement of being compliant to the mood of the PwD, in terms of their willingness to lie in the rocking chair, which could vary each day or from hour to hour. The only difficulty that the care staff encountered was the occasional refusal to rock by the PwD. These refusals were assessed as restlessness and a desire to leave the unit and return to their home, from which the care staff could not always distract the PwD. When the person was willing to use the rocking chair, it was a viable intervention for BPSD and an overall relaxing and enjoyable activity for the PwD.

The whole care staff was positive toward the use of a rocking chair in their future care for PwD. The rocking chairs continue to remain in a peaceful corner in the respective three units. The chairs are used by the PwD who wish to do so, and have therefore become an ordinary part of the everyday care for PwD.

\section{Discussion}

\subsection{Result Considerations}

Overall, the quantitative and the qualitative data were consistent with each other and indicated that the use of Wellness Nordic Relax ${ }^{\circledR}$ Chair reduced BPSD and increased the quality of life for some of the PwD included in the present study. In regard to care staff, it was a feasible, usable, non-labor-intensive, non-pharmacological intervention in their care for PwD. However, there is no one-size-fits-all care for the PwD. Even when the PwD may exhibit similar diagnoses for dementia, individual differences supersede the diagnoses, which might explain why the use of Wellness Nordic Relax ${ }^{\circledR}$ Chair had a positive effect on certain PwD and not on others. Moreover, several challenges had to be dealt with during the intervention phase owing to the cognitive impairment of the PwD, as discussed in a previous research work by Lepore, Shuman, Wiener, and Gould [38]. The importance of executing the intervention protocol was often not understood by the PwD, which at times was the reason for their agitation and aggressive behavior. In order to not violate 
the PwD's personal integrity and to avoid raising ethical issues, the care staff had to comply with the PWD's behavior and wait until a later time to commence the use of a rocking chair. Previous studies conducted with PWD involving the use of rocking chairs have reported similar difficulties. In a study evaluating a glider swing conducted by Snyder and colleagues [18], the PwD's dissent was mood- or behavior-oriented and varied with each rocking session.

Mean, median, and relative change measures indicated improvement in BPSD, such as aberrant motor behavior, agitation, apathy, depression, irritability, and night-time behavior disturbances, as well as in the quality of life of the PwD. However, these improvements appeared to be brief, as they were not preserved until the post-intervention period. In summary, the use of Wellness Nordic Relax ${ }^{\circledR}$ Chair produced positive, although short-lived outcomes, similar to the findings of Snyder and colleagues [18]. Furthermore, as the frequency and severity of BPSD were relatively low during the pre-intervention, there was little room left for the decreased BPSD resulting from the intervention.

Besides the quantitative data, qualitative data were collected in the form of care staff's notes written in conjunction with each rocking session. In addition, the study concluded with a group interview, in which nine of the eleven care staff members participated. Instead of considering the data collection as sequentially explanatory (where quantitative data has the priority), data collection should be viewed as a concurrent case triangulation where both quantitative and qualitative data are assigned equal weights [39]. The qualitative data revealed that the PwD immensely enjoyed relaxation during the use of the rocking chair, and the associated positive effects would continue for a while after the use. At times, the positive effects would revert into agitation, irritability, or aberrant motor behavior a few hours after the use, whereupon the care staff would introduce the rocking chair to the PwD once again. Therefore, it would be misleading to evaluate the intervention for each PwD only in terms of quantitative assessments performed biweekly, as it would disregard the individual experiences in the rocking chair, which occurred at least five times per week. It would rather be more beneficial to analyze both quantitative and qualitative data for the overall understanding of the potential value of the use of Wellness Nordic Relax ${ }^{\circledR}$ Chair. Furthermore, the daily notes from the care staff were informative to the next professional caregiver when he/she would present the rocking chair to the PwD. These notes, in addition to providing guidance to the care staff, assisted in promoting inter-rater reliability.

The present study did not explore the possible effects that the level of dementia might have exerted on the outcomes of the intervention. Previous research [18, 19] suggests that rocking/swinging intervention produces more positive emotions in people with less cognitive impairment, and those who enjoy rocking more than others can be benefited more.

\subsection{Methodological Considerations}

There are several key issues of concern associated with involving PwD as the research participants, including recruitment, research ethics, the processes of informed consent and assent/dissent to participate in the research, communication challenges, and reliability of the data [36]. Since obtaining a signed informed consent from the PwD was not always possible, the assent/dissent process was considered carefully throughout the study; participation assent was obtained from the PwD at the beginning of every rocking session so as to uphold the ethical principles. In all cases, the next of kin (for example, spouse or children) or the trustees were asked 
if they objected to the PwD's participation in the study, as it was questionable whether the PwD could communicate relatively consistently, understand the basic information regarding the choices, evaluate the implications of different choices, and rationally comprehend the risks and benefits associated with the different options offered $[40,41]$. Since these capacities fluctuated over time and different decisions required different levels of capacity, a diagnosis of dementia or even a specific score on a cognitive test were not the only criteria for determining the decision-making capacity [41].

Data evaluation in an SCR study focuses on whether the intervention could be identified to be responsible for the change in the data measurements. A limitation of the present study was that there were a limited number of data points collected during the intervention and postintervention, which restricted the number of choices of data evaluation methods for the researchers. The methods of data evaluation other than visual analysis, such as time series, interrupted time series, and percentage of all non-overlapping data (PAND), could have generated further reliable results, although these are not recommended for short, single-baseline SCR studies such as the present study [42]. Visual inspection has been and continues to be the dominant and the most reliable method for data evaluation in SCR studies [23, 35], which is the reason for it being selected for the present study. Nonetheless, whether it was the intervention or the other factors that influenced the change remains to be deciphered. Therefore, it remains to be clarified which qualities of the rocking chair, among the rocking movement and tactile stimulation, the music, the U-shaped pillow, and the blanket, that improved or worsened the BPSD.

The intervention protocol specified several factors regarding the implementation of the intervention. However, as it is typical with the experimental studies, the impact on the outcome associated with the different requirements of the PwD for seclusion when using the rocking chair and the assessment bias among the care staff when assessing the PWD's BPSD and quality of life could not be controlled. A systematic assessment bias for apathy was observed in PwD 6, which resulted in reduced inter-rater reliability and explained the variable data during the preintervention (when two care staff members conducted the assessment) and stable data during the intervention (when only one care staff member conducted the assessment). The variability of the data and identification of potential bias were possible due to the nine data points that were collected during the three-week pre-intervention period, which is six data points more than the minimum number recommended by Skolasky [25]. It is recommended that in future SCR studies, assessments for each PwD should be performed by only one care staff member or jointly by two care staff members. Furthermore, since each PwD received the exclusive presence of a care staff member until she became more relaxed in the rocking chair, the Hawthorne effect could emerge as another limitation [43]. This effect implies that the participants in a research study may change their behavior simply due to the extra attention received, irrespective of any experimental manipulation. Since no control was applied for this effect in the present study, it might have altered the PWD's BPSD and quality of life.

SCR studies in clinical settings present several challenges for the researchers. The additional dimension of participants with cognitive impairments requires thoughtful attention from the researchers. It is possible to anticipate certain problems, such as the progression of dementia, employee turnover, and disturbances in the surroundings, and not the others.

The present study was conducted in only one nursing home, and it is, therefore, not possible to generalize the results, although the results would be credible if the readers recognize the 
descriptions or interpretations as comparable to their own experiences [44]. Accordingly, the results may be transferable to other comparable situations and contexts.

\section{Conclusions}

The obtained data from the present study suggested that the use of the Wellness Nordic Relax ${ }^{\circledR}$ Chair provided short-term relief from aberrant motor behavior, agitation, apathy, depression, irritability, and night-time behavior disturbances, along with an increase in the quality of life of the PwD. Therefore, the use of Wellness Nordic Relax ${ }^{\circledR}$ Chair may complement the nonpharmacological management techniques for the care of PWD in nursing homes.

\section{Acknowledgments}

We wish to express our sincere gratitude to the participants who shared their experiences and perceptions so generously with us. We also thank Eskilstuna Municipality for professional collaborations. Special thank you to Statistician Anna Ekholm at FoU i Sörmland for advice on and review of the data analysis.

\section{Additional Materials}

The data material generated during the current study is available from the corresponding author upon request.

\section{Author Contributions}

Christine Gustafsson designed and planned the study. Annelie K Gusdal planned the study, implemented the intervention, collected and analysed the data. Annelie K Gusdal wrote the major part of the manuscript in critical discussion with Christine Gustafsson. Both authors have approved the final version submitted to OBM Geriatrics.

\section{Funding}

This study was made possible through the collaboration between the Department of Care and Support Management at Eskilstuna Municipality, Måsta Äng Academic Nursing Home, and the School of Health, Care and Social Welfare at Mälardalen University. The company ErgoNova Sweden made the study possible by lending the rocking chairs to Måsta Äng Academic Nursing Home.

\section{Competing Interests}

The authors have declared that no competing interests exist.

\section{References}

1. World Health Organization. Fact sheet: Dementia [Internet]. WHO; 2019 [cited 2019 Oct 13]. Available from: https://www.who.int/news-room/fact-sheets/detail/dementia 
2. Prince $M$, Wimo A, Guerchet M, Ali GC, Wu YT, Prina M. World Alzheimer Report 2015: The global impact of dementia. An analysis of prevalence, incidence, cost and trends. London: Alzheimer's Disease International; 2015.

3. Cerejeira J, Lagarto L, Mukaetova-Ladinska EB. Behavioral and psychological symptoms of dementia. Front Neurol. 2012; 3: 1-23.

4. Kales HC, Gitlin LN, Lyketsos CG. Assessment and management of behavioral and psychological symptoms of dementia. BMJ. 2015; 350: h369.

5. Gaugler JE, Kane RL, Kane RA, Clay T, Newcomer R. Caregiving and institutionalization of cognitively impaired older people: Utilizing dynamic predictors of change. Gerontologist. 2003; 43: 219-229.

6. Fraser LA, Liu K, Naylor KL, Hwang YJ, Dixon SN, Shariff SZ, et al. Falls and fractures with atypical antipsychotic medication use: A population-based cohort study. JAMA Intern Med. 2015; 175: 450-452.

7. Wang PS, Schneeweiss S, Avorn J, Fischer MA, Mogun H, Solomon DH, et al. Risk of death in elderly users of conventional vs. atypical antipsychotic medications. N Engl J Med. 2005; 353: 2335-2341.

8. Dyer SM, Harrison SL, Laver K, Whitehead C, Crotty M. An overview of systematic reviews of pharmacological and non-pharmacological interventions for the treatment of behavioral and psychological symptoms of dementia. Int Psychogeriatr. 2018; 30: 295-309.

9. Laver K, Cumming RG, Dyer SM, Agar MR, Anstey KJ, Beattie E, et al. Clinical practice guidelines for dementia in Australia. Med J Aust. 2016; 204: 191-193.

10. Sorbi S, Hort J, Erkinjuntti T, Fladby T, Gainotti G, Gurvit H, et al. EFNS-ENS guidelines on the diagnosis and management of disorders associated with dementia. Eur J Neurol. 2012; 19: 1159-1179.

11. Cohen-Mansfield J. Nonpharmacologic interventions for inappropriate behaviors in dementia. Am J Geriatr Psychiatry. 2001; 9: 361-381.

12. McDermott O, Charlesworth G, Hogervorst E, Stoner C, Moniz-Cook E, Spector A, et al. Psychosocial interventions for people with dementia: A synthesis of systematic reviews. Aging Ment Health. 2019; 23: 393-403.

13. Orgeta V, Qazi A, Spector A, Orrell M. Psychological treatments for depression and anxiety in dementia and mild cognitive impairment: Systematic review and meta-analysis. $\mathrm{Br} \mathrm{J}$ Psychiatry. 2015; 207: 293-298.

14. Tsoi KKF, Chan JYC, Ng YM, Lee MMY, Kwok TCY, Wong SYS. Receptive music therapy is more effective than interactive music therapy to relieve behavioral and psychological symptoms of dementia: A systematic review and meta-analysis. J Am Med Dir Assoc. 2018; 19: 568-576.

15. Legere LE, McNeill S, Schindel Martin L, Acorn M, An D. Nonpharmacological approaches for behavioural and psychological symptoms of dementia in older adults: A systematic review of reviews. J Clin Nurs. 2018; 27: e1360-e1376.

16. van der Steen JT, Smaling HJA, van der Wouden JC, Bruinsma MS, Scholten R, Vink AC. Music-based therapeutic interventions for people with dementia. Cochrane Database Syst Rev. 2018; 7: CD003477.

17. Laver K, Dyer S, Whitehead C, Clemson L, Crotty M. Interventions to delay functional decline in people with dementia: A systematic review of systematic reviews. BMJ Open. 2016; 6: e010767. 
18. Snyder $M$, Tseng $Y$, Brandt $C$, Croghan $C$, Hanson $S$, Constantine $R$, et al. A glider swing intervention for people with dementia. Geriatr Nurs. 2001; 22: 86-90.

19. Watson NM, Wells TJ, Cox C. Rocking chair therapy for dementia patients: Its effect on psychosocial well-being and balance. Am J Alzheimers Dis. 1998; 13: 296-308.

20. Niemelä K, Väänänen I, Leinonen R, Laukkanen P. Benefits of home-based rocking-chair exercise for physical performance in community-dwelling elderly women: A randomized controlled trial. Aging Clin Exp Res. 2011; 23: 279-287.

21. Pierce C, Pecen J, McLeod KJ. Influence of seated rocking on blood pressure in the elderly: A pilot clinical study. Biol Res Nurs. 2009; 11: 144-151.

22. Cross RL, White J, Engelsher J, O'Connor SS. Implementation of rocking chair therapy for veterans in residential substance use disorder treatment. J Am Psychiatr Nurses Assoc. 2018; 24: 190-198.

23. Kazdin AE. Single-case research designs: Methods for clinical and applied settings. 2nd ed. New York: Oxford University Press; 2011. p. 463.

24. Lobo MA, Moeyaert M, Baraldi Cunha A, Babik I. Single-case design, analysis, and quality assessment for intervention research. J Neurol Phys Ther. 2017; 41: 187-197.

25. Skolasky RL Jr. Considerations in writing about single-case experimental design studies. Cogn Behav Neurol. 2016; 29: 169-173.

26. Wellness Nordic Relax ${ }^{\circledR}$ Chair/ErgoNova Gungstolen ${ }^{\circledR}$ Available from: https://wellnessnordic.com/produktsortiment/sansestole/ http://www.ergonova.se/gungstolskoncept/ergonova-gungstolen/

27. Fredriksson AC, Hellström L, Nilsson U. Patients' perception of music versus ordinary sound in a postanaesthesia care unit: A randomised crossover trial. Intensive Crit Care Nurs. 2009; 25: 208-213.

28. MusiCure. Copenhagen and Denmark: Gefion Records; 2009 [cited 2019 Oct 10]. Available from: http://www.musicure.com/

29. Mullen B, Champagne T, Krishnamurty S, Dickson D, Gao RX. Exploring the safety and therapeutic effects of deep pressure stimulation using a weighted blanket. Occup Ther Ment Health. 2008; 24: 65-89.

30. Cummings JL. The Neuropsychiatric Inventory: Assessing psychopathology in dementia patients. Neurology. 1997; 48: S10-S16.

31. Melander C, Sävenstedt S, Olsson M, Wälivaara BM. Assessing BPSD with the support of the NPI-NH: A discourse analysis of clinical reasoning. Int Psychogeriatr. 2018; 30: 581-589.

32. Falk $\mathrm{H}$, Persson LO, Wijk H. A psychometric evaluation of a Swedish version of the Quality of Life in Late-Stage Dementia (QUALID) scale. Int Psychogeriatr. 2007; 19: 1040-1050.

33. Weiner MF, Martin-Cook K, Svetlik DA, Saine K, Foster B, Fontaine CS. The quality of life in late-stage dementia (QUALID) scale. J Am Med Dir Assoc. 2000; 1: 114-116.

34. Hsieh HF, Shannon SE. Three approaches to qualitative content analysis. Qual Health Res. 2005; 15: 1277-1288.

35. Lane JD, Gast DL. Visual analysis in single case experimental design studies: Brief review and guidelines. Neuropsychol Rehabil. 2014; 24: 445-463.

36. World Medical Association. Declaration of Helsinki: Ethical principles for medical research involving human subjects. WMA; 2018 [cited 2019 Sept 23]. Available from: 
https://www.wma.net/policies-post/wma-declaration-of-helsinki-ethical-principles-formedical-research-involving-human-subjects/

37. International Committee of Medical Journal Editors, ICMJE. Recommendations for the Protection of Research Participants [Internet]. 2019 [cited 2019 Sep 23]. Available from http://www.icmje.org/recommendations/browse/roles-andresponsibilities/protection-ofresearch-participants.html

38. Lepore M, Shuman SB, Wiener JM, Gould E. Challenges in involving people with dementia as study participants in research on care and services. Research summit om dementia care. Building evidence for services and supports. 2017 [cited 2019 Oct 1].

39. Creswell JW, Plano Clark VL. Designing and conducting mixed methods research. 3rd ed. Thousand Oaks, CA: Sage Publications; 2017. p. 520.

40. Karel MJ, Gurrera RJ, Hicken B, Moye J. Reasoning in the capacity to make medical decisions: The consideration of values. J Clin Ethics. 2010; 21: 58-71.

41. Woods B, Pratt R. Awareness in dementia: Ethical and legal issues in relation to people with dementia. Aging Ment Health. 2005; 9: 423-429.

42. Parker RI, Hagan-Burke S, Vannest K. Percentage of All Non-Overlapping Data (PAND): An alternative to PND. J Spec Ed. 2007; 40: 194-204.

43. Sedgwick P, Greenwood N. Understanding the Hawthorne effect. BMJ. 2015; 351: h4672.

44. Sandelowski M. Focus on qualitative methods: The use of quotes in qualitative research. Res Nurs Health. 1994; 17: 479-482.

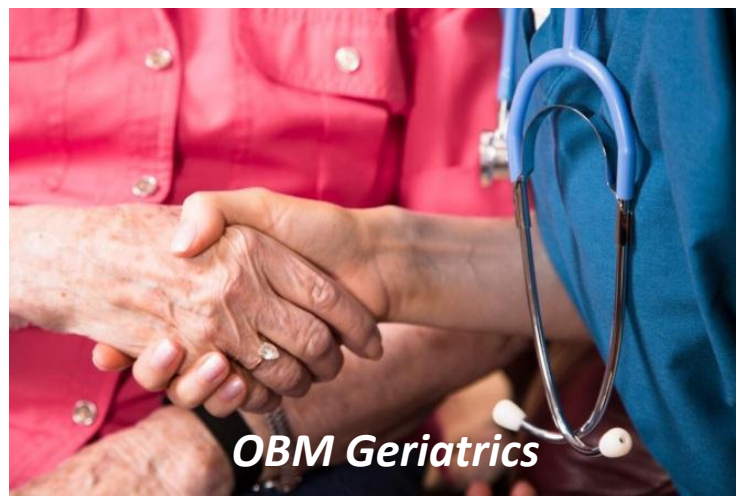

Enjoy $O B M$ Geriatrics by:

1. Submitting a manuscript

2. Joining in volunteer reviewer bank

3. Joining Editorial Board

4. Guest editing a special issue

For more details, please visit: http://www.lidsen.com/journals/geriatrics 